\title{
SAÚDE, JUDICIALIZAÇÃO E PATERNALISMO NO ESTADO SOCIAL EM CRISE
}

\author{
HEALTH, JUDICIALIZATION AND PATERNALISM IN THE \\ WELFARE STATE CRISIS
}

RESUMO: O texto aborda o fenômeno da judicialização da saúde no estado social brasileiro. Pretende analisar as particularidades do direito à saúde em sede de políticas públicas e o fenômeno da judicialização, caracterizando a política pública brasileira de saúde, a relação entre ineficiência e justiciabilidade de direitos e abordar criticamente o comportamento do Poder Judiciário. Possui metodologia predominantemente qualitativa, que conta com técnicas de pesquisa bibliográfica e documental. Do estudo realizado infere-se que a saúde, enquanto direito social, deve ser concretizada por intermédio de políticas públicas, frente a ineficiência estatal em efetivar o direito à saúde o Poder Judiciário é provocado para reestabelecer a autoridade constitucional. Analisada a conduta do Judiciário nos casos que envolvem o direito à saúde é clara a sua interferência em matérias essencialmente políticas, como o orçamento público e as escolhas de prioridades dentro das políticas públicas de saúde. Conclui-se que a atuação voluntarista não estimula positivamente a implementação do welfare state, mas antes viola a democracia e a separação dos poderes, vez que decisões de natureza política passam a ser tomadas no âmbito judicial, caracterizando um paternalismo ilusório e inconsequente.

PALAVRAS-CHAVE: Direito à saúde; Judicialização; Paternalismo; Estado social; Democracia.

ABSTRACT: The text addresses the phenomenon of health judicialization in the brazilian social state. It aims to analyze the particularities of the right to health in public policies and the phenomenon of judicialization, caressing brazilian public health policy, the relationship between inefficiency and justiciability of rights, and critically addressing the behavior of the Judiciary. It has a predominantly qualitative methodology, which relies on bibliographic and documentary research techniques. From the study carried out that health, as a social right, must be concretized through public policies, in the face of the inefficiency of the State in effecting the right to health, the Judiciary is provoked to reestablish constitutional authority. Having analyzed the judiciary's conduct in cases involving the right to health, it is clear that it interferes in essentially political matters, such as the public budget and the choice of priorities within public health policies. It is concluded that voluntary action does not positively stimulate the implementation of the welfare state, but rather violates democracy and the separation of powers, since decisions of a political nature are taken in the judicial sphere, characterizing an illusory and inconsequential paternalism.

KEYWORDS: Right to health; Judicialization; Paternalism; Welfare State; Democracy.

\footnotetext{
${ }^{1}$ Mestrando pelo PPGD/UFC. Especialista em Direito e Processo eleitoral pela Universidade Cândido Mendes/ RJ.

2 Mestranda pelo PPGD/UFC. Especialista em Direito Tributário pela UNIDERP e em Direito Penal pelo Damásio de Jesus.
} 


\section{INTRODUÇÃO}

A Constituição Federal de 88 inaugurou o welfare state na realidade do Brasil, estabelecendo muitos direitos essenciais à preservação da dignidade humana. $\mathrm{O}$ direito à saúde está previsto na Constituição de 1988 como direito social dos cidadãos brasileiros, porém, a implementação da proteção da saúde por parte do Poder público padece de muitos problemas, o que incentiva os administrados a buscarem o Poder Judiciário para verem corporificados seus direitos. Neste sentido a temática deste estudo aborda a judicialização do direito à saúde no Brasil.

A importância do desenvolvimento de estudos nesta seara se justifica pela imbricada relação entre sociedade e Constituição. Ao passo em que a Constituição garante direitos aos indivíduos, estes direitos por sua vez, em sua eficácia ou ineficácia afetam diretamente o desenvolvimento social positivo e digno. No contexto da judicialização da saúde há divergência entre realidade constitucional e realidade social, o que deve ser analisado pela ciência jurídica com intuito de maximizar a efetivação material da Constituição impactando proficuamente no desenvolvimento social digno e sustentável, respeitando os limites da democracia.

A problemática da pesquisa se volta para a resposta das seguintes indagações: Como caracterizar a política pública de saúde? O que gera o deslocamento das decisões em políticas públicas de saúde dos Poderes democraticamente legitimados para o Judiciário? Como deve atuar o Poder Judiciário - diante da gigantesca judicialização - para institucionalizar o Estado Democrático de Direito Social?

Constitui objetivo primordial deste texto analisar as particularidades do direito à saúde em sede de políticas públicas e o fenômeno da judicialização, caracterizando a política pública brasileira de saúde, a relação entre ineficiência e justiciabilidade de direitos e abordar criticamente o comportamento do Poder Judiciário.

A metodologia utilizada é predominantemente qualitativa buscando compreender o fenômeno da judicialização da saúde e a confusão entre a Política e o Direito, se aproveitando também de breves considerações quantitativas para reforçar o pensamento desenvolvido no campo teórico. Conta com técnica de pesquisa bibliográfica, discutindo o tema abordado a partir de doutrina de referência e especializada. E, também, com técnica de análise 
documental, explorando decisões do Supremo Tribunal Federal, porém, com um número de amostragem estrategicamente reduzido intuindo especificamente demonstrar determinadas tendências de contrassenso nas decisões da Corte, contrastando decisões paradigmáticas como a ADPF 45 e STA 175 com outras posteriores, de 2015 a 2016, como as STA 76, STA 815 e AgR 977.190.

Depreende-se do exame feito que o Sistema Único de Saúde - SUS constitui política pública bem estruturada, contendo programa, ação-coordenação e processos administrativos específicos. Problemas na prestação das ações e serviços de saúde tornam o SUS ineficiente, causando assim o quadro de judicialização em demasia. Da atuação do Judiciário se constata que há a interferência clara em matéria política, como orçamento e escolhas de prioridades, que por sua vez não são cabíveis na seara judicial, ainda que a pretexto da negligência dos Poderes políticos. A ação voluntarista dos magistrados é um "encanto", o paternalismo judiciário não contribui para a implementação do welfare state.

$\mathrm{O}$ estudo se divide em três tópicos. O primeiro aborda a caracterização da política pública brasileira de saúde. O segundo investiga os problemas da saúde pública brasileira e sua relação com a judicialização. E, por fim, o terceiro e último tópico aborda o encantamento que constitui a atuação voluntarista do Judiciário como alternativa à negligência do Poder público.

\section{DA POLÍTICA PÚBLICA EM SAÚDE}

Uma das considerações mais aceita em conceito de políticas públicas é a feita por Thomas Dye (1984) ao concluir que política pública é aquilo que o governo decide fazer ou não, entendendo inclusive que não fazer algo em relação à certa demanda também é uma forma de política pública. Mas não subsiste uma definição particular de políticas públicas, este termo se reinventa conceitualmente com o decorrer do tempo (AGUM, RISCADO \& MENEZES, 2015).

Políticas públicas, de maneira genérica, são ações governamentais, diretas e indiretas, que perseguem o bem-estar dos indivíduos (PETERS, 1986). Assim como no campo da Ciência Política o conceito de política pública gera uma dificuldade de definição conceitual 
no âmbito do Direito, sendo um grande desafio o delineamento do conceito jurídico deste instituto (BUCCI, 2006).

Indiscutível é que sobre o Direito se fundam as ações governamentais que tendem a melhorar a qualidade de vida dos cidadãos e concretizar o Estado de bem-estar social. Daí surge a importância de um conceito que permita a discussão jurídica de políticas públicas enquanto ações governamentais dentro do Estado de Direito.

O Estado Social inaugura um modelo no qual as pessoas possuem direitos, como saúde, educação e desporto, por exemplo, direitos estes que independem de suas condições sociais e devem ser protegidos pelo Estado a partir da utilização de políticas públicas capazes de transformar o status quo de determinada sociedade, contribuindo para o desenvolvimento social, econômico e político.

Jorge Luiz Bolzan de Morais e Guilherme Brum explicam que o Walfare State provocou uma espécie de "[...] complexificação nesse modelo estatal, o que o teria deixado com um perfil ainda mais interventor" (2016, p. 13). O Estado Democrático de Direito, que passa a ser qualificado igualmente como "social", passa a ser caracterizado por um desejo transformador manifestado especialmente com a constitucionalização dos direitos sociais. Neste contexto ocorre um encontro entre o Direito e a Política, aquilo que constitui dever do Estado para com os cidadãos e está formalmente expresso na legislação e a forma com que os direitos serão conformados.

Maria Paula Dallari Bucci (2006) busca descrever políticas públicas como sistema que sirva de exemplo ao Executivo e Legislativo e propõe o seguinte conceito:

\section{É o programa de ação governamental que resulta de um processo ou conjuntos de processos juridicamente regulados [...] visando coordenar os meios à disposição do Estado e as atividades privadas, para a realização de objetivos relevantes e politicamente determinados (2006, p. 39).}

Do conceito proposto por Bucci (2006) extraem-se elementos que caracterizam um conceito jurídico de política pública, quais sejam o (a) programa, (b) ação-coordenação e o (c) processo.

Por programa entenda-se o arranjo administrativo para se alcançar determinado resultado. O conteúdo programático de uma política pública deve destacar os objetivos a serem perseguidos, internamente os instrumentos e formas de avaliação, e externamente as ferramentas instrumentais e de procedimento, além da forma de captação de recursos. A açãocoordenação está ligada à utilização de uma política pública para a consecução de um objetivo 
determinado previamente (ação) e o alinhamento entre a política pública escolhida e o objeto a ser alcançado (coordenação). Por fim o processo deve ser compreendido com o conjunto de etapas procedimentais que levam a um fim - a conformação de um direito/alteração do status quo - combinado com a participação daqueles que tenham interesse na matéria programática da política pública.

O direito à saúde está inscrito no artigo $6^{\circ}$ da Constituição Federal de 1988, bem como entre os artigos 196 e 200. O regramento constitucional da saúde é extremamente claro quanto ao programa, ação-coordenação e processo, sendo o Sistema Único de Saúde - SUS uma verdadeira e inovadora política pública.

Um sistema único é instituído na Constituição com o objetivo de proteção da saúde com a redução de riscos e outros agravamentos e acesso universalizado e igualitário aos serviços decorrentes deste direito. As políticas sociais e econômicas são definidas como instrumentos na persecução da concretização do direito à saúde e aos termos de lei posterior são confiados outros aspectos, que por sua vez caracterizam o SUS.

A Lei ${ }^{\circ} 8.080$ de 1990 avança na orientação de melhor definir o SUS no Brasil. O artigo $4^{\circ}$ do instrumento normativo supracitado nomeia as ações e serviços de saúde como Sistema Único de Saúde, determina que a iniciativa privada poderá participar do SUS em caráter suplementar; os artigos $5^{\circ}$ e $6^{\circ}$ determinam seus objetivos, dentre eles a "identificação e divulgação dos fatores condicionantes e determinantes da saúde", formulação de política de saúde e "assistência às pessoas por intermédio de ações de promoção, proteção e recuperação da saúde, com a realização integrada das ações assistenciais e das atividades preventivas", por exemplo; o artigo $7^{\circ}$ define os princípios e diretrizes do SUS; e o artigo $8^{\circ}$ trata da organização, direção e gestão; definindo a Lei $n^{\circ} 8.080$ muitos outros aspectos importantes do SUS.

A Lei $n^{\circ}$ 8.142, também de 1990, delibera sobre a participação da população na gestão do SUS, esclarecendo que esta deverá acontecer por intermédio da Conferência de Saúde e dos Conselhos de Saúde, além de prescrever a afetação dos recursos oriundos do Fundo Nacional de Saúde (FNS).

No ano 2000 com a Emenda Constitucional n 29 restou expresso que as ações e serviços de saúde gozariam de financiamento advindo dos recursos alocados para a 
seguridade social, além de um gasto mínimo a ser realizado com gastos em saúde pela União, Estados, Distrito Federal e Municípios.

Diante dos instrumentos jurídicos anteriormente citados é possível depreender que o SUS é política pública por ser expressão da ação governamental na busca pela concretização do direito à saúde. Do SUS inúmeras outras políticas públicas são geradas, isso decorre de seu caráter universal, descentralizado, regionalizado, hierarquizado, racional, contando com a participação popular na sua gestão e do setor privado de forma complementar, sobretudo por meio de convênios. Toda essa complexidade gera um emaranhado de políticas públicas sanitárias.

O Sistema Único de Saúde pode ainda ser enquadrado dentro do conceito proposto por Maria Paula Dallari Bucci (2006). O SUS detém o objetivo de promover, proteger e recuperar a saúde dos indivíduos, tendo como instrumentos políticas sociais e econômicas, processo de avaliação e recursos para custeio, o que caracteriza o chamado programa. A utilização de políticas sociais e econômicas para a concretização da saúde constitui a ação e o alinhamento entre política e objetivo a coordenação. Por derradeiro o processo no âmbito do SUS é determinado pelos procedimentos administrativos que devem ser utilizados para a solidificação do direito à saúde e a gestão participativa por via de Conferência e Conselhos de Saúde.

De toda sorte, mesmo o SUS sendo uma das políticas públicas mais delineadas pelas regras jurídicas constitucionais e infraconstitucionais este padece de graves problemas no caminho da conformação do direito à saúde no Brasil. São latentes as incapacidades do SUS diante de uma demanda extremamente alta, o que torna as políticas públicas em saúde solo copioso para a proposição de demandas judiciais reivindicando o cumprimento da promessa instalada pela Constituição Federal de 1988 de que a saúde é direito de todos e dever do Estado.

\section{INEFICIÊNCIA E JUDICIALIZAÇÃO}

O Sistema Único de Saúde constitui uma das políticas públicas mais bem estruturadas dentro do cenário brasileiro. Porém, a concretização do direito à saúde por intermédio do SUS 
enfrenta grande dificuldade prática. Pesquisa realizada pelo IBOPE revela que a insatisfação do brasileiro com o SUS é expressiva. Os dados são alarmantes e servem para demonstrar que “algo está errado" na execução da política pública de saúde brasileira.

A população brasileira avalia negativamente os serviços de saúde no Brasil. Para 61\% dos entrevistados a qualidade do sistema público de saúde do país é "péssima" ou "ruim". Apenas $10 \%$ consideram a qualidade "ótima" ou "boa". Entre os entrevistados $42 \%$ não percebem mudança no sistema público de saúde e 43\% consideram que piorou. Ou seja, para $85 \%$ da população brasileira a situação da saúde pública no país não avançou nos últimos anos. (CNI-IBOPE, 2012, p. 13-14).

A intranquilidade em relação ao sistema público de saúde só aumenta ao passo em que se volta o olhar a outros dados, como, por exemplo, "hospitais públicos obtêm nota média geral de 5,7 [...]" (CNI-IBOPE, 2012, p. 10). Muitos problemas foram apontados no âmbito da rede pública, entre eles seguem a demora no atendimento; falta de equipamentos; falta de médicos; más condições das unidades de saúde; má administração/corrupção; falta de medicamentos; e a superlotação. São incapacidades que revelam incoerência entre a estruturação legal do SUS enquanto política pública de saúde e a realidade experimentada pelos cidadãos usuários.

Em pesquisa realizada pelo Instituto Datafolha em julho de 2014, encomendada pelo Conselho Federal de Medicina, a maior parte da população entrevistada se mostrou insatisfeita com a saúde pública no Brasil. A pesquisa revelou que $92 \%$ da população classificou a saúde com notas entre $0-7$, em uma escala que chegava a 10. Em relação ao SUS $87 \%$ dos entrevistados o classificaram com notas de 0 a 7 , e, 53\% destes em um intervalo de 0 a 4 (DATAFOLHA, 2014).

A pesquisa buscou investigar a facilidade de acesso e disponibilidade dos serviços de saúde na rede pública, principalmente em relação às cirurgias, atendimento médico, remédios distribuídos gratuitamente e outros aspectos. O que espaventa é o fato de que, em relação a todos os aspectos investigados, o nível máximo de dificuldade de acesso foi identificado em escala igual ou superior a $43 \%$ nos atendimentos. Os medicamentos tiveram a menor avaliação como de "acesso muito difícil" alcançando o nível de $43 \%$ na totalidade das vezes em que se recorreu à saúde pública, já as cirurgias chegaram à marca de $67 \%$ das avaliações como de "acesso muito difícil” (DATAFOLHA, 2014). 
Em 2016 o Instituto Datafolha voltou a realizar pesquisa, novamente solicitada pelo Conselho Federal de Medicina, para apurar a percepção dos brasileiros em relação às instituições e profissionais de saúde. Na opinião de $37 \%$ dos entrevistados a saúde é o principal problema do Brasil, $82 \%$ dos participantes da pesquisa utilizaram a rede pública de saúde e a classificação do SUS foi expressivamente tendente ao nível ruim/péssimo (65\%). Sobre as ações que deveriam ser adotadas para maximização da qualidade dos serviços públicos de saúde $58 \%$ dos participantes apontaram o aumento do número de profissionais de saúde e 50\% o aumento no número de leitos oferecidos (DATAFOLHA, 2016).

Note-se que o sistema público de saúde vem sendo mal avaliado consecutivamente por seus usuários. É um sintoma flagrante de que a prática da política pública em saúde não está em acordo com o disposto na letra da lei. O Sistema Único de Saúde vem se tornando precário, é o que se pode inferir da percepção dos brasileiros nos últimos anos.

O Poder Executivo, em sua administração, falha na execução da política pública. Não consegue estruturar a máquina administrativa para a efetivação do direito à saúde (programa), é relapso no que toca ao alinhamento entre a política pública e o objetivo constitucional a se alcançar (ação-coordenação) e consequentemente não gerencia adequadamente as etapas procedimentais particulares da política pública para poder alterar o status quo da sociedade (processo). A ineficiência da política pública é manifestação explícita da dificuldade da Administração Pública em tornar efetivo o direito à saúde previsto no texto constitucional (CAMBI, 2009), é expressão latente do menoscabo com o texto fundante do Estado brasileiro. Neste cenário, constatada a violação à Lei fundamental, o Poder Judiciário é compulsado a atuar no sentido de reestabelecer a autoridade constitucional dentro da perspectiva da justiciabilidade do direito à saúde.

A Constituição Federal em seu artigo $5^{\circ}, \mathrm{XXXV}$, assegura que lesão ou ameaça a direito deve ser apreciada pelo Judiciário, desta feita os graves problemas que acometem o SUS justificam a provocação do Estado jurisdicional para agir no sentido de garantir o direito à saúde.

Casos relativos à saúde cresceram significativamente nos últimos 7 anos. De acordo com o Conselho Nacional de Justiça e o Ministério da Saúde entre 2010 e 2015 os custos com o cumprimento de decisões judiciais referentes à saúde foram de 3,2 bilhões. Em 2016 o gasto foi de 1,6 bilhão. Em 2017 as despesas já atingiram o valor de R\$ 730,6 milhões e deve 
chegar até o número de 7 bilhões (CIEGLINSKI, 2017). Aumento de mais de $700 \%$ nos gastos da União em saúde resultante de verdadeiras batalhas judiciais (BRASIL, 2017). As demandas são tantas que o Ministério da Saúde disponibilizou, em julho de 2017, o sistema $S$ code, que controla todas as questões judicializadas, quanto para fins de defesa processual quanto para o cumprimento das determinações (BOND, 2017).

$\mathrm{O}$ aumento no número de questões judicializadas resulta tanto da falta de eficácia da política pública de saúde como igualmente da emancipação e apropriação dos cidadãos em relação aos direitos sociais (PIOVESAN, 2015), que conhecedores de seus direitos os reivindicam no contexto judicial. A saúde é vista, pós Constituição de 88 , como um direito e não mais uma caridade decorrente de programas e políticas estatais, devendo ser concretizada imediatamente, revelando então a face do compromisso constitucional com a integração social, solidariedade e igualdade (EIDE e ROSAS, 1995). É também consequência do Estado social determinado pela Constituição de 1988, que por sua própria gênese é intervencionista, requerendo “[...] sempre a presença militante do poder político nas esferas sociais" (BONAVIDES, 1961, p. 239).

O Poder Judiciário, chamado a dar provimento em demandas que envolvem o direito à saúde, finda por se localizar em um limite extremamente cinzento entre aquilo que é político e aquilo que é jurídico, posição que por si, exige muita cautela. Os magistrados podem contribuir sinergicamente para a institucionalização do Estado Democrático de Direito ou atuar arbitrariamente. A efetivação de políticas públicas de saúde, em menor ou maior grau, envolve escolhas essencialmente políticas - programa, ação-coordenação e processo.

O Supremo Tribunal Federal - STF em sede de controle direto de constitucionalidade reconheceu no julgamento da Ação de Descumprimento de Preceito Fundamental - ADPF n ${ }^{\circ}$ 45 o "perfil político do Poder Judiciário". Nesta ADPF buscou-se impugnar veto presidencial - à Lei de diretrizes orçamentarias - que por sua essência em tese violaria a vinculação de recursos mínimos para a implementação do direito à saúde conforme preconiza a EC 29/2000. Mesmo a questão do veto tendo sido superada na seara política, o STF não deixou de se pronunciar na orientação de pacificar a competência do Judiciário para interferir nas questões de políticas públicas, inclusive na temática orçamentária, desde que reste comprovada a negligência governamental. De acordo com o voto do ministro relator Celso de Mello (BRASIL, 2004) ainda que não figure como competência constitucional do Judiciário, de 


\section{글 REVISTA ACADÊMICA FACULDADE DE DIRETIO DO RECIFE}

maneira particular da Corte Constitucional brasileira, a tarefa de formular e implementar políticas públicas de saúde, em caráter excepcional o Judiciário - configurada a inércia dos Poderes originalmente competentes - poderá atuar tendo em vista a violação de direitos individuais e/ou coletivos insculpidos nos preceitos constitucionais, respeitando os limites orçamentários, a razoabilidade e a separação dos poderes.

Em 2009 o STF realizou Audiência Pública (N4) reunindo representantes da Administração Pública, Ministério Público, Advocacia Geral da União e a sociedade civil organizada. O intuito da audiência repousou na discussão de parâmetros objetivos para as decisões envolvendo direito à saúde. Com um debate extremamente polarizado, por um lado os que negam a possibilidade de intervenção judicial e de outro os que a defendem, a audiência findou com a criação de um grupo de trabalho voltado para investigar as possibilidades de atuação judiciária nos casos discutidos, que posteriormente desaguou na edição da Resolução n ${ }^{0} 107$ do Conselho Nacional de Justiça - CNJ, dando origem ao Fórum da Saúde, com objetivo precípuo de orientar os magistrados em suas decisões (BRITO, 2017).

No julgamento da Suspensão de Tutela Antecipada 175, um dos mais paradigmáticos julgados pós audiência pública, o STF pareceu reconhecer os limites da judicialização. O voto do ministro relator Gilmar Mendes, ratificado em plenário, registrou a existência de critérios explicitamente objetivos a serem seguidos quando do deferimento de pedidos referentes ao direito fundamental à saúde. Com base nesta decisão especificamente é possível concluir que (1) o Poder Judiciário pode determinar a concretização do direito constitucional desde que evidenciada a existência de política pública anterior e a falha da Administração Pública; (2) não existindo política pública anterior o pleito não pode ser deferido; (3) no caso de tratamento equivalente existente no sistema público de saúde, este será preferido em detrimento do solicitado; e (4) ante a inexistência de política pública, se o tratamento demandado for comprovado em eficácia o pedido pode ser concedido.

Na ADPF 45 o STF declara o perfil político do Judiciário, e, posteriormente, discutiu na Audiência Pública $\mathrm{n}^{\circ} 4$ critérios para decisões envolvendo saúde, critérios estes que restaram cristalinos na STA 175. Todavia o comportamento jurisprudencial do STF é outro. Em sede de controle difuso de constitucionalidade os parâmetros estabelecidos na STA 175 não são seguidos. 
No pedido suspensivo de tutela em Agravo Regimental 815 do estado de São Paulo (DJ 05/06/2015) o Supremo confirmou a obrigação do Estado em arcar com tratamento de alto custo para hepatite tipo "C", ainda que os medicamentos solicitados referentes ao tratamento não sejam reconhecidos pela ANVISA e consequentemente ausentes na lista de dispensação do SUS. No entendimento do Supremo também não restara comprovada lesão ao orçamento público.

Do julgamento da STA 761 do DF (DJ 29/05/2015) o posicionamento da Corte Suprema é o mesmo. Obrigou o Distrito Federal a custear intervenção terapêutica de alto custo contra patologia genética raríssima com fármaco não avaliado pela ANVISA e também não previsto na política nacional de dispensação de medicamentos de alto custo do SUS.

Em nova demanda, por ocasião do AGRE 977.190/MG (DJ 09/11/2016), o Supremo decidiu que a lista de medicamentos do Sistema Único de Saúde não é parâmetro exclusivo para a análise de pedidos de tratamento terapêutico, não merecendo reforma a sentença agravada, visto que a avaliação médica é que determina a melhor conduta clínica de intervenção.

\section{O CANTO DA SEREIA: PATERNALISMO NO ESTADO SOCIAL EM CRISE (?)}

A princípio é preciso revelar que se há crise em relação ao welfare state no Brasil esta não diz respeito à sua essência, mas antes sim à sua implementação. Paul Pierson (1998) esclarece que o termo "crise" pode ser tomado a partir de quatro dimensões: (a) situação de perturbação advinda de impacto externo; (b), lapso temporal dramático anterior a uma superação situacional; (c) problema em larga escala; e, por último (d) a exteriorização de um paradoxo de longo prazo.

É necessário professar a noção de Estado social no Brasil a partir da perspectiva de Pierson (1998) em conceber o estado de crise como a manifestação de um paradoxo, uma contradição duradoura. Ao contrário do que acontecera nos estados europeus - a implementação clara de um Estado social compromissado com os direitos sociais, justiça distributiva e cidadania (BENTO, 2003) - no Brasil a consolidação do estado de bem-estar social não aconteceu. $\mathrm{Na}$ verdade, em toda a América Latina o estado social não teve um 
marco temporal certo e igualmente próspero de sua institucionalização. A realidade latinoamericana é marcada por características que efetivamente impediram a conformação evidente e eficaz do bem-estar social, tais como o processo de colonização, governos autoritários, desenvolvimento retardado, etc., aumentando desta forma "[...] as distâncias sociais e o processo de empobrecimento das populações" (STRECK e MORAIS, 2006, p. 81), abismo claro entre as disposições constitucionais democráticas e sua materialidade.

No Brasil, de forma particular, o welfare state tem percorrido um longo caminho em busca de sua solidificação. De acordo com Paulo Bonavides (2012) a Constituição de 1934 originou-se - com um viés social influenciado pela Carta de Weimar - pontuando a inauguração de uma democracia de bem-estar, firmando compromisso com a justiça social, e, ainda, sendo resposta a um modelo de Brasil que priorizava os interesses políticos e “[...] econômicos de uma elite rural aristocrática e parasita" (TORRES, 2004, p. 143). A Constituição de 1934 traçou pacto com direitos sociais de maneira tacanha e ainda assim o arcabouço constitucional não se consumou (BARROSO, 2000).

A trajetória do constitucionalismo social brasileiro de 1934 até 1988 é contundida por “[...] crises, golpes de Estado, insurreição, impedimentos, renúncia e suicídio de presidentes, bem como queda de governos, repúblicas e Constituições" (BONAVIDES, 2012, p. 378). E mesmo com o advento da Constituição de 1988, extensa, analítica e altamente social, o Estado não conseguiu em sua realidade material institucionalizar o welfare state $\mathrm{O}$ processo de modernização do Brasil no século XX tomou os rumos de uma burocracia administrativa nos moldes weberianos que desconsiderou as necessidades mais essenciais dos cidadãos (AVRITZER, 2002).

A reforma administrativa da década de 90 - perseguidora da eficiência - que se iniciou em meio a uma grave crise econômica buscou um meio de desenvolvimento estabelecido num sistema de “[...] dependência econômica associada, na qual as multinacionais seriam a fonte do desenvolvimento brasileiro, sendo o crescimento do país associado à poupança externa” (NOHARA, 2012, p. 130), sobrando explícito um desenvolvimento neocolonial que desprezou "[...] os objetivos constitucionais de construção de uma sociedade mais justa e solidária” (NOHARA, 2012, p. 130). Para Eric Hobsbawn (1995, p. 555) o Brasil pode ser tido como um "monumento à negligência social". 
A má percepção dos serviços públicos de saúde, como constatado pelo Ibope e Instituto Datafolha, demonstra que a institucionalização do estado de bem-estar social hodiernamente é um desafio. O Poder Público tem dificuldades na concretização de direitos sociais. Feitas estas considerações é possível afirmar que no Brasil o welfare state não "está em crise", mas antes a sua implementação constitui a verdadeira crise, uma manifestação de contradição entre os termos constitucionais e a realidade social experimenta pelos cidadãos. Diante dos estorvos na concretização do Estado social brasileiro, especialmente frente aos problemas que enfrentam o Sistema Único de Saúde e seus usuários, é fundamental que o Poder Judiciário atue para a institucionalização da democracia de bem-estar, esta possibilidade de atuação é fruto da supremacia da Constituição, "da importância de seu conteúdo material” (SOUZA NETO; SARMENTO, 2017, p. 23).

É plausível afirmar então que diante da inércia e negligência dos Poderes políticos, notadamente Executivo e Legislativo, em satisfazerem os objetivos constitucionais o Judiciário pode atuar para afirmar os direitos fundamentais dos cidadãos, forçando o Estado a cumprir com a programação constitucional. Nesse sentido Ronald Dworkin (2005) assevera que os magistrados, dentro do judicial review, podem tomar decisões essencialmente políticas com a finalidade de garantir direitos fundamentais, no entanto, estão limitados a afirmar "o que" o Estado deve concretizar e não "como" deverá o fazer.

A partir da crise de institucionalização do estado social - da ausência de concretização do direito à saúde de maneira particular - o Poder Judiciário tem sido provocado reiteradas vezes a intervir nesta seara (item 2 do texto) e, mesmo sendo forçoso afirmar, sua jurisprudência tem caminhado na orientação de não somente afirmar os direitos fundamentais dos cidadãos, mas indo além, nos últimos anos passou a determinar a forma de como o direito à saúde deve ser concretizado. Discorda-se desta lógica onde o Judiciário se impõe como “responsável constitucional" para implementar políticas públicas de saúde, interferindo no orçamento do Estado e desprezando a legislação infraconstitucional no que toca o direito sanitário (não observar a exclusividade da lista de medicamentos do SUS como parâmetro para decisões judiciais - AGRE 977.190/MG).

Como bem preceitua José Antonio Avelãs Nunes (2010) é compreensível humanamente o comportamento judicial que obriga a implementação do direito à saúde e determina os meios e formas para tal tarefa, porém, do aspecto constitucional democrático é 
inconcebível que os Tribunais, especialmente o STF, se deixem levar por esta "tentação" face a "incapacidade crónica dos demais Poderes, ocupados por interesses que muitas vezes não coincidem com os dos cidadãos eleitores" (NUNES, 2010, p. 14).

Homero escreveu há quase três mil anos uma de suas principais obras, Odisseia, narrando a história de Ulisses, rei da Ilha de Ítaca que se juntara a outros gregos e venceram uma guerra contra Troia, e, no retorno para Ítaca enfrentaram inúmeros prélios. Homero enarra a resistência de Ulisses e seus comandados em referência as sereias. No retorno para casa o trajeto se aproximaria da Ilha de Capri, região rochosa e cheia de "sereias". Ulisses sabia do grande poder de encantamento das serias por meio de seus cantos suaves e agudos, a dispersão provocada nos homens levava as embarcações à destruição em meios as pedras e os tripulantes lançavam-se ao mar. Astuto, Ulisses ordenou que seus marinheiros usassem cera nos ouvidos, obstando o encantamento, porém, não recorreu a esta saída, ordenou que fosse amarrado ao mastro da embarcação e que não fosse liberto enquanto não estivesse ultrapassada a região de Capri. Quando passava pela ilha, Ulisses ao ouvir as sereias, desesperadamente solicitou que fosse desamarrado, contudo, os marinheiros não o ouviam, igualmente não ouviam as sereias. Ulisses pode auscultar o canto das sereias e sobreviver (HOMERO, 2005).

Metaforicamente o Poder Judiciário pode ser comparado a Ulisses, e, a exemplo deste, não pode ceder aos encantos que a judicialização da saúde possui sob pena de colocar em risco o regime democrático.

Em 2004 na ADPF 45 o Supremo Tribunal Federal - STF declara o perfil político do Judiciário, dimensão que incluiria até mesmo a interferência no orçamento público para fins de consubstanciação dos objetivos constitucionais, institucionalização do Estado social. Em 2006 o Superior Tribunal de Justiça - STJ, no julgamento do REsp 832.317/RS, entendeu ser possível o bloqueio de recursos diretamente nas contas públicas, podendo o art. art. $461, \S 5^{\circ}$, do Código de Processo Civil de 1973 ser interpretado conforme a Constituição no sentido de efetivar tutela específica. Avelãs Nunes (2010) explica que até mesmo a impenhorabilidade dos bens públicos passou a ser mitigada nesta questão.

Este movimento é interferência visível do Poder Judiciário em questões puramente políticas, usurpando o lugar do administrador público para fazer escolhas de prioridades que essencialmente não lhe competem. Constitui risco ao regime democrático. Ao contrário de 
Ulisses o Judiciário não "pôs" a cera nos ouvidos e o barco da democracia tende a se chocar contra as pedras de um autoritarismo judicial. A oportunidade para uma atuação voluntarista no cenário da judicialização à saúde constitui um verdadeiro "canto da sereia", ao invés de institucionalizar a democracia e o regime social finda por supervalorizar a supremacia do Poder Judiciário por si e não pela Constituição.

$\mathrm{Na}$ STA 175 o STF estabelece limites para as demandas que envolvem o direito à saúde, o que pacificaria em tese a jurisprudência, mas os juízes singulares e Tribunais de Justiça continuam concedendo demandas em saúde de maneira indiscriminada e o Supremo Tribunal Federal confirma as decisões em sede de controle de constitucionalidade difuso, violando seus próprios critérios objetivos para demandas judiciais em saúde anteriormente definidos. É o que se pode constatar das decisões nos julgamentos da STA 815/SP, STA 761/ DF e AgR 977.190/MG. O Supremo ratifica a decisão do juízo a quo, inclusive para garantir prestação de medicamentos que não foram aprovados pela ANVISA e não constam nos programas de dispensação do SUS. Na decisão mais recente, AgR 977.190/MG de 2016, o Supremo afirma que a lista de medicamentos do SUS, a Relação Nacional de Medicamentos Essenciais - RENAME, não pode ser tida como parâmetro único para decisões nestes casos.

A substância fosfoetanolamina fora vinculada como a "cura do câncer" por volta dos últimos meses do ano de 2014. A composição criada no laboratório de Química da Universidade de São Paulo (USP) passou a ser distribuída por um docente com a promessa de combater efetivamente as células cancerígenas, mas não havia, assim como ainda não há, nenhuma comprovação científica de sua eficiência. A USP emitiu a Portaria $n^{0}$ 1389/2014 no intuito de proibir a distribuição da substância ante a desobediência das regras legais de direito sanitário para realização de testes clínicos e demais procedimentos.

Nos primeiros dois meses de 2016 a Universidade de São Paulo já contava com 16.000 ordens judiciais para o fornecimento de fosfoetanolamina sintética (SANTOS et al, 2017). Havia ainda a prospecção de que este número dobrasse nos próximos meses do ano. Conceder medidas liminares obrigando instituição de ensino superior pública a fornecer substância sem comprovação de eficácia, ainda ausentes os testes clínicos e demais procedimentos previstos em legislação específica, é flagrantemente ilegal. Questão controversa ainda é a responsabilização por complicações na saúde do demandante decorrente do uso da fosfoetanolamina. A responsabilidade por eventuais complicações clínicas recai sobre o 
magistrado que decide, o médico que emite parecer no processo ou a instituição que é obrigada a fornecer a substância? Muitas indagações, sem respostas.

É incompreensível como o Poder Judiciário passa a conceder medidas liminares sem nenhuma preocupação com a legislação sanitária, inclusive a pretexto de uma interpretação constitucional da dignidade da pessoa humana e do direito à saúde inserida dentro de uma nova hermenêutica que se sobrepõe à própria Constituição de 1988 e às normas sanitárias.

O artigo 197 da Constituição Federal determina que é competência do Poder Público, nos termos da lei, a regulamentação, fiscalização e controle das ações e serviços de saúde. No artigo seguinte, 198, o constituinte determina a vinculação dos recursos em matéria de saúde.

A lei no 8.080 de 1990 preconiza que é atribuição da União, Estados, Distrito Federal e Municípios a definição de instâncias e mecanismos de controle, avaliação e fiscalização das ações e serviços de saúde; administração dos recursos orçamentários e financeiros para a saúde em cada ano; e, elaborar normas técnico-científicas de promoção, proteção e recuperação da saúde.

A lei 6.360 de 1976 que dispõe sobre a regulamentação de medicamentos, insumos farmacêuticos, drogas e outros, pontua:

\begin{abstract}
Art. $1^{\circ}$ - Ficam sujeitos às normas de vigilância sanitária instituídas por esta Lei os medicamentos, as drogas, os insumos farmacêuticos e correlatos [...].

Art. $2^{\circ}$ - Somente poderão extrair, produzir, fabricar, transformar, sintetizar, purificar, fracionar, embalar, reembalar, importar, exportar, armazenar ou expedir os produtos de que trata $\mathrm{o}$ Art. $1^{\circ}$ as empresas para tal fim autorizadas pelo Ministério da Saúde e cujos estabelecimentos hajam sido licenciados pelo órgão sanitário das Unidades Federativas em que se localizem.
\end{abstract}

A Constituição e a legislação infraconstitucional acima mencionadas tornam evidente a competência em matéria orçamentaria, regulatória, organizatória e fiscalizatória das ações e serviços em saúde. Não há como compatibilizar com tal legislação as decisões judiciais citadas neste estudo. O Judiciário lança-se ao mar e deixa que a democracia se arrebente diante das pedras da ilha da judicialização. É um comportamento jurisprudencial que viola a separação dos poderes e o regime democrático, e ainda mais, não incita os Poderes políticos a desempenharem suas funções constitucionais, uma vez que o Judiciário se tornou a arena de garantia de direitos.

Ulisses foi gigante por reconhecer que precisava se amarrar a algo para não ceder às tentações, tinha ciência de sua incapacidade de livre não sucumbir ao canto das sereias. $\mathrm{O}$ Judiciário precisa se assemelhar a Ulisses, reconhecer que pode muito, mas não pode tudo, 
precisa "se amarrar as leis". Se tudo pudesse não faria sentido uma Constituição que harmoniosamente distribui competências e funções entre poderes estatais.

Com fulcro nos casos citados durante o desenrolar do texto é factível atestar a interferência do Judiciário em questões estritamente políticas, seja na seara orçamentária ou em escolhas políticas de prioridades no que se refere à saúde. O movimento de interferência judicial em questões políticas, como o caso da judicialização da saúde, somente favorece o processo de "infantilização" dos sujeitos políticos (MAUS, 2000). A sociedade, então "órfã", passa a confirmar esta infantilização (incapacidade de implementação do welfare state) dos agentes políticos que se acomodam, e, passa a ver no "terceiro poder", o Judiciário, a imagem de um pai que gere suas necessidades (MAUS, 2000).

Ingeborg Maus (2000, p. 185) explica que “[...] o retorno mais marcante da imagem do pai parece revelar-se no exame da jurisdição constitucional dos Estados Unidos", consequentemente a imagem do terceiro poder paternalista no Brasil se empodera pela influência norte-americana no constitucionalismo brasileiro.

Como se viu na análise jurisprudencial realizada, tanto no controle de constitucionalidade difuso quanto no concentrado, a percepção é de que o terceiro poder é de fato um pai para a sociedade, que implementa o direito à saúde sob qualquer custo. A consciência do bem-estar social passa a morar não mais nas escolhas políticas que devem ser feitas pelos poderes democraticamente legitimados, mas sim numa consciência do juiz sobre o que é a moral social (Community morality), fator determinante das decisões estudadas.

A projeção de um paternalismo no Judiciário elimina as discussões e procedimentos das escolhas políticas, por sua vez consensuais. A saúde deve ser protegida pelo Estado por intermédio de políticas sociais e econômicas. O SUS é a política pública de saúde brasileira, donde inúmeras outras políticas se originam. É política pública estruturada por um programa, ação-coordenação e por processos. Quando as decisões em matéria de saúde se deslocam do Executivo e Legislativo para o Poder Judiciário, este, deveria afirmar o direito constitucional (art. $6^{\circ}$ e 196 ss da $\mathrm{CF} / 88$ ), todavia o Judiciário tem realizado as escolhas do programa, da ação e coordenação e também das etapas procedimentais que devem ser seguidas, as escolhas políticas passam a residir no plano da consciência do julgador.

Estando as escolhas políticas inseridas dentro da consciência de moral social do magistrado, quem as controlará? Ingeborg Maus (2000, p. 187) responde que “[...] Quando a 


\section{REVISTA ACADÊMICA iil.}

Justiça ascende ela própria à condição de mais alta instância moral da sociedade, passa a escapar de qualquer mecanismo de controle social - controle ao qual normalmente se deve subordinar toda instituição do Estado em uma forma de organização política democrática".

O paternalismo do terceiro poder se torna incontrolável. O contingenciamento do orçamento público para o cumprimento de decisões judiciais em 2017 supera a marca de 730 milhões de reais. O valor previsto pelo Ministério da Saúde para a satisfação das demandas judiciais impacta negativamente o SUS enquanto política pública, prejudicando-o e priorizando direitos individuais.

A propensão é que o valor contingenciado para despesas da judicialização cresça nos próximos 19 anos em decorrência da Emenda Constitucional 95, que congelou os gastos públicos, limitando o crescimento do gasto com saúde ao valor da inflação salvo na hipótese de corte de despesa em outra área. Em outros termos, não haverá um crescimento real nos gastos públicos, o que consequentemente aumentará a procura pelo Judiciário.

A limitação dos gastos públicos no Brasil é de vinte anos, com previsão de revisão em dez anos, contrariando experiência de países como a Holanda, Finlândia e Suécia que utilizaram o controle de gastos em prazos que não excederam cinco exercícios financeiros (INTERNATIONAL MONETARY FUND, 2015). Considerando este cenário, como controlar decisões judiciais que limitam ainda mais os gastos públicos em saúde e privilegiam direitos individuais?

A atividade financeira do Estado impõe à toda a sociedade "[...] poder-dever de participação não apenas como beneficiários da realização das despesas públicas, mas também como agentes do controle e credores [...] de manejos de recursos e realização de despesas" (TORRES, 2014, p. 150). Como comedir a atuação do Judiciário paternalista que impõe a concretização de direitos individuais prejudicando políticas públicas voltadas para uma coletividade que já sofre pela precariedade dos serviços públicos, e, agora tende a padecer mais ainda? Como induzir o Judiciário a priorizar a escolha de políticas públicas coletivas em um cenário no qual a desigualdade no acesso à justiça é evidente? É possível o Judiciário findar com o SUS judicial para maximizar o SUS legal?

Refrear o terceiro poder paternalista é atividade no mínimo complexa, para não dizer impossível, considerando o fato de que "[...] toda menção [pelo Judiciário] a um dos princípios superiores ao direito escrito leva [...] à suspensão das disposições 
normativas" (MAUS, 2000, p. 189). A judicialização da saúde constitui um estímulo à Justiça paternalista, à Justiça como o superego da sociedade. Nota-se que o Judiciário, o grande Ulisses desta Odisseia democrática que é o Brasil, não tem se amarrado ao mastro da lei.

A concretização de políticas públicas de saúde a qualquer custo pelo Judiciário no Brasil representa a conciliação entre as teorias de Carl Schimtt e Hans Kelsen. O Judiciário paternalista desempenha tanto a função de soberano político - figura popularmente ungida pela sociedade órfã - que interfere diretamente no direito (SCHIMTT, 1996) quanto a de defesa da Constituição como Tribunal (KELSEN, 1995). É ao mesmo tempo, guardião e senhor da Constituição. Genuína anomalia no Poder Judiciário que "preserva" a Constituição ao tempo em que também a viola.

Os Tribunais não podem configurar-se como arena para saneamento de sensibilidades materiais sociais de um Estado que contemporaneamente luta pela institucionalização do Estado Democrático de Direito Social. Os distúrbios de um Estado social em construção e até mesmo a opinião pública não justificam o abandono do arcabouço normativo vigente (NOVELINO, 2015).

As sereias não existem. Os belos cantos se davam pela fúria dos ventos contra as rochas de Capri, provocando assim sons aguçados e auditivamente aprazíveis. Com razão esteve Ulisses que evitou a tragédia pelo encantamento. Igualmente deve ser o Poder Judiciário no Brasil contemporaneamente. A atuação voluntarista dos magistrados não é alternativa para a crise de implementação do welfare state. O paternalismo do terceiro poder (MAUS, 2000) antes obstaculiza a conformação do Estado social porque prejudica as escolhas administrativas e orçamentárias do administrador público. Aparentemente contribuindo para a solidificação dos objetivos constitucionais consuma, na verdade, prejuízo para políticas públicas universais como o SUS.

A eficiência na consolidação do Estado de bem-estar social está diretamente ligada à democracia (GABARDO, 2003), envolve a “[...] dimensão da racionalidade e otimização no uso dos meios" (GROTI, 2014, p. 277) e a "[...] qualidade da ação administrativa que obtém resultados satisfatórios" (GROTI, 2014, p. 277), portanto, o Judiciário não é instituição competente para atuar nesta esfera. 


\section{CONSIDERAÇÕES FINAIS}

Sem dúvidas o direito à saúde (art. $6^{\circ}$ da CF) é indispensável a dignidade dos cidadãos brasileiros e condição material fundamental para o exercício de todos os direitos previstos na Carta Constitucional de 1988, devendo ser protegido por intermédio de políticas sociais e econômicas universais e integrais.

Conforme as disposições constitucionais o Sistema Único de Saúde - SUS (art. 196 e ss) é verdadeiramente uma grande política pública, que encontra estrutura infraconstitucional nas leis $\mathrm{n}^{\mathrm{o}} 8.080$ e $\mathrm{n}^{\mathrm{o}} 8.142$ de 1990. Enquanto política pública é composto por um (a) programa, objetivando a garantia da proteção à saúde, com mecanismos de avaliação e custeio próprios; (b) ação-coordenação, alinhando o objetivo e a estrutura de política pública adequada; e (c) processo, envolvendo as etapas administrativas para o alcance eficiente do objetivo. É espaço que comporta escolhas essencialmente políticas.

Porém, mesmo com um arcabouço jurídico extremamente delineado e claro, definidor de objetivos, custeio e avaliação, a saúde enfrenta grandes desafios em sua concretização, como se pode inferir das pesquisas empíricas realizadas pelo CNI - Ibope e Instituto Datafolha. Os cidadãos usuários do SUS o qualificam negativamente em decorrência da dificuldade de acesso aos seus serviços ou à má prestação deles. A dificuldade de acesso aos serviços de proteção da saúde e a ausência de qualidade e eficiência é violação direta a mandamentos constitucionais. Viola direito fundamental do cidadão. Desta feita parte da população finda por provocar o Poder Judiciário para ver garantida a proteção do direito à saúde, judicializando questões nesta matéria. O fenômeno da judicialização da saúde tem aumentando bastante nos últimos anos, o que abre margem para uma atuação judicial que pode ser sinérgica para a concretização do Estado Democrático de Direito Social ou um empecilho a este modelo estatal.

A análise feita da jurisprudência do Supremo Tribunal Federal - STF - ADPF 45; Audiência Pública 4; STA 175; STA 815; STA 761; AgR 977.190 - demonstra que ficou reconhecida a possibilidade de concretização do direito à saúde pelo Judiciário no exercício de seu perfil político. Em seguida o STF buscou a instalação de critérios para a judicialização em saúde, mas a boa realidade é que os magistrados não seguem os parâmetros criados para tais demandas. O Poder Judiciário vem interferindo em questões orçamentárias abertamente, 
deferindo pleitos que solicitam medicamentos não reconhecidos pela ANVISA e ausentes da Relação Nacional de Medicamentos Essenciais - RENAME. Defere, em sede de pedidos antecipatórios, até mesmo substâncias que não têm eficácia comprovada clinicamente, como é o caso da fosfoetanolamina sintética, que sequer passou por procedimentos de teste.

Diante desta exposição é claro que a atuação do Judiciário interfere diretamente em questões políticas, definindo novos objetivos para a política pública de saúde (medicamentos e/ou tratamentos faltosos da estrutura do SUS) e obrigando o contingenciamento de recursos para a satisfação de suas decisões.

A judicialização, por si, fruto de um constitucionalismo com sistema de freios e contrapesos é admissível se compreendida como um estímulo aos Poderes políticos a corrigirem suas falhas, mas de toda sorte a via judicial enquanto âmbito de implementação do Estado Social é inconcebível dentro da lógica democrática.

Por mais que as dificuldades de solidificação do welfare state - e concretização de direitos sociais no Brasil - pareçam uma boa oportunidade do Judiciário restaurar a autoridade do texto constitucional a sua atuação não deve ser voluntarista, usurpando as funções e competências de Poderes legitimados democraticamente, o que significa um óbice ao estado democrático social. É decifrável o grande encanto que a judicialização da saúde constitui aos Tribunais, porém, estes devem tornar-se Ulisses na democracia brasileira, reconhecendo suas limitações e se amarrando às normas constitucionais e sanitárias brasileiras.

A alternativa para o fortalecimento do Estado social não é um Judiciário paternal (podendo ser inclusive autoritário) para com a sociedade, isto é uma ilusão, pois, o contingenciamento de milhões no orçamento para a satisfação de determinações judiciais impacta negativamente o SUS, além do que a seara da política pública de saúde envolve, para além da legitimidade democrática em questão orçamentária, as escolhas de prioridades que o administrador público deve fazer em sua discricionariedade.

Diante do exposto, é notório que a judicialização da saúde tem ganhado proporções muito grandes, demandando do Poder Judiciário posicionamento frente à negligência dos poderes políticos em concretizarem o direito fundamental à saúde. Todavia, a judicialização não pode se tornar arena para a institucionalização do estado social e corporificação de direitos, a atuação voluntarista do Poder Judiciário, que concede pedidos de forma alheia às normas constitucionais e infraconstitucionais, violando a separação dos poderes, o princípio 
democrático, a legalidade e contingenciando milhões na área da saúde, não constitui meio sinérgico para a institucionalização do Estado Democrático de Direito Social, mas antes a obstaculiza.

\section{REFERÊNCIAS}

AGUM, Ricardo.; RISCADO, Priscila.; MENEZES, Monique. Políticas públicas: conceitos e análises em revisão. Revista Agenda Política: UFSC, 2015.

AVRITZER, Leonardo. Modelos de deliberação democrática: uma análise do orçamento participativo no Brasil. In: Santos, Boaventura de Sousa (Org). Democratizar a democracia: os caminhos da democracia participativa. Rio de Janeiro: Civilização brasileira, 2002, p. 561-598.

BARROSO, Luís R. O direito constitucional e a efetividade de suas normas: limites e possibilidades da constituição brasileira. Rio de Janeiro: Renovar, 2000.

BENTO, Leonardo Valles. Governança e governabilidade na reforma do estado: entre eficiência e democratização. Barueri: Manole, 2003.

BONAVIDES, Paulo. Curso de direito constitucional. São Paulo: Malheiros, 2012.

. Do estado liberal ao estado social. São Paulo: Saraiva, 1961.

BOND, Letycia. Saúde disponibiliza software para controlar ações judiciais no setor. 2017. Disponível em: < http://agenciabrasil.ebc.com.br/geral/noticia/2017-07/saudedisponibiliza-software-para-controlar-acoes-judiciais-no-setor>. Acesso em: 23 set. 2017.

BRASIL. Constituição. Constituição da República Federativa do Brasil de 1988. Disponível em: http://www.planalto.gov.br/ccivil_03/Constituicao/Constitui\%C3\%A7 ao.htm . Acesso em: 17 set. 2017.

. Lei $\mathbf{n}^{\mathbf{0}}$ 8.142, de 28/12/1990. Disponível em: http://www.editorasolucao.com.br/ media/materialcomplementar/UNCISAL/09-1eis-8080-8142+LC-141+9394.leg.pdf>. Acesso em: 22 set. 2017.

. Lei $n^{0} 8.080$ de 19 de setembro de 1990. Disponível em: < http:// www.planalto.gov.br/ccivil_03/Leis/L8080.htm>. Acesso em: 17 jun. 2017.

. Ministério da Saúde. Ações judiciais impactam até R\$ 7 bilhões no SUS. 2017. Disponível em: < http://portalsaude.saude.gov.br/index.php/cidadao/principal/agenciasaude/25275-ministro-da-saude-fala-sobre-impacto-de-acoes-judiciais-no-sus $>$. Acesso: 23 set. 2017.

- Ministério da Saúde. Secretaria de Políticas de Saúde. Política Nacional de Medicamentos. Brasília: Ministério da Saúde, 2001.

Supremo Tribunal Federal. Arguição de descumprimento de preceito fundamental - 45/DF. Relator: Min. Celso de Mello. Julgamento em 29/04/04. Pesquisa de jurisprudência. Disponível em: < http://www.sbdp.org.br/arquivos/material/ 343_204\%20ADPF\%202045.pdf>. Acesso em: 30 ago. 2017. 


\section{REVISTA ACADÊMICA}

FACULDADE DE DIRETIO DO RECIFE

. Supremo Tribunal Federal. Audiência Pública no 4. 2009. Disponível em: < http://www.stf.jus.br/portal/cms/verTexto.asp?servico=processoAudienciaPublicaSaude $>$. Acesso em: 23 set. 2017.

. Supremo Tribunal Federal. STF - STA: 175 CE. Relator: Min. PRESIDENTE, Data de Julgamento: 18/09/2009, Data de Publicação: DJe-182 DIVULG 25/09/2009. Disponível em: < http://www.stf.jus.br/arquivo/cms/noticianoticiastf/anexo/sta175.pdf > . Acesso em: 25 set. 2017.

. Supremo Tribunal Federal. STF - STA: 815 SP - SÃO PAULO. Relator: Min. Presidente, Data de Julgamento: 18/12/2015, Data de Publicação: DJe-010 01/02/2016. Disponível em: < http://redir.stf.jus.br/paginadorpub/paginador.jsp? docTP=TP\&docID=8625237>. Acesso em: 25 set. 2017.

. Supremo Tribunal Federal. STF - STA: 761 DF. Relator: Min. Presidente, Data de Julgamento: 26/11/2014, Data de Publicação: DJe-235 DIVULG 28/11/2014 PUBLIC 01/12/2015. Disponível em: < http://redir.stf.jus.br/paginadorpub/paginador.jsp? docTP=TP\&docID=8590045> . Acesso em: 25 set. 2017 .

. Supremo Tribunal Federal. STF - Ag. Rg. No Recurso Extraordinário com agravo 977.190 MG. Relator Min. Ricardo Lewandoswki. Data de julgamento: 09/11/2016. Divulgação: 22/11/2016. Disponível em: < http://redir.stf.jus.br/paginadorpub/paginador.jsp? docTP=TP\&docID=12071365> . Acesso em: 25 set. 2017.

. Superior Tribunal de Justiça. STJ - REsp: 832317 RS 2006/0062218-9. Relator: Ministro João O. de Noronha. Data de Julgamento: 19/09/2006. Data de Publicação: DJ 08/11/2006, p. 178.

BRITO, Patrícia Ribeiro. Judicialização da saúde e desarticulação governamental: uma análise a partir da audiência pública da saúde. In: BUCCI, Maria Paula Dallari.; DUARTE, Clarice Seixas. (Orgs.). Judicialização da saúde: a visão do Poder Executivo. São Paulo: Saraiva, 2017, p. 203-239.

BUCCI, Maria Paula Dallari. O conceito de política pública em Direito. In: BUCCI, Maria P. D. (Coord.). Políticas públicas: reflexões sobre o conceito jurídico. São Paulo: Saraiva, 2006, p. $1-47$.

CAMBI, Eduardo. Neoconstitucionalismo e neoprocessualismo: direitos fundamentais, políticas públicas e protagonismo judiciário. São Paulo: Editora RT, 2009.

CIEGLINSKI, Thaís. CNJ avança para qualificar decisões judiciais com gastos em saúde. 2017. Disponível em: < http://www.cnj.jus.br/noticias/cnj/84486-cnj-avanca-na-qualificacaoda-judicializacao-para-otimizar-gasto-de-saude> . Acesso: 27 de set. 2017.

CNI IBOPE. Retratos da sociedade brasileira: saúde pública. Brasília: CNI, 2012.

DATAFOLHA. Opinião dos brasileiros sobre o atendimento na área de saúde. São Paulo: Instituto Datafolha, 2014. Disponível em: $<$ http://portal.cfm.org.br/images/PDF/apresentaointegra-datafolha203.pdf>. Acesso em: 12 jul. 2017.

DATAFOLHA. Percepção dos brasileiros sobre a confiança e credibilidade em profissionais e instituições. São Paulo: IPD, 2016.

DWORKIN, Ronald. Uma questão de princípio. São Paulo: Martins Fontes, 2005. 
DYE, Thomas. Understanding public policy. Englewood Cliffs, NJ: Prentice Hall, 1984.

EASTON, David. A framework for political analysis. Englewood Cliffs: Prentice Hall, 1965.

EIDE, Asbjorn.; ROSAS, Allan. Economic, social and cultural rights: a universal challenge. In: EIDE, A; KRAUSE, Catarina.; ROSAS, Allan. (Orgs). Economic, social and cultural rigths. Dordrecht, Boston e Londres: Martinus Nijhoff Publishers, 1995, p. 3-9.

GABARDO, Emerson. Eficiência e legitimidade do estado: uma análise das estruturas simbólicas do direito político. Barueri: Manole, 2003.

GROTTI, Dinorá. Eficiência administrativa: alargamento da discricionariedade acompanhado do aperfeiçoamento dos instrumentos de controle e responsabilização dos agentes públicos um panorama possível?. In: MELLO, Celso A. B. de.; FERRAZ, Sergio.; ROCHA, Silvio L. F.; SAAD, Amauri Feres. (Coords). Direito administrativo e liberdade. São Paulo: Malheiros, 2014, p. 273-309.

HOBSBAWN, Eric. A era dos extremos. Trad. De Marcos Santarrita. São Paulo: Cia das Letras, 1995.

HOMERO. Odisseia. Lisboa: Livros Cotovia, 2005.

INTERNATIONAL MONETARY FUND. Expenditure rules: effective tools for sound fiscal policy?. Disponível em: https:/www.imf.org/external/pubs/ft/wp/2015/wp1529.pdf. Acesso em: 13 ago. 2017.

KELSEN, Hans. Quién debe ser el defensor de la Constitución?. Madrid: Tecnos, 1995.

MAUS, Ingeborg. Judiciário como superego da sociedade: o papel da atividade jurisprudencial na sociedade órfã. 2000. Disponível em: < $\underline{\text { http:// }}$ www.direitocontemporaneo.com/wp-content/uploads/2014/02/JUDICI\%C3\%81RIO-COMOSUPEREGO-DA-SOCIEDADE.pdf > . Acesso: 11 de set. 2017.

MORAIS, José Luis B.; BRUM, Guilherme Valle. Políticas públicas e jurisdição constitucional. Porto Alegre: Livraria do Advogado, 2016.

NOHARA, Irene Patrícia. Reforma administrativa e burocrática: impacto da eficiência na configuração do direito administrativo brasileiro. São Paulo: Atlas, 2012.

NOVELINO, Marcelo. O STF e a opinião pública. In: SARMENTO, Daniel. Jurisidição constitucional e política. Rio de Janeiro: Forense, 2015, p. 243-272.

NUNES, Avelãs. Os tribunais e o direito à saúde. 2000. Disponível em: < https:// edisciplinas.usp.br/pluginfile.php/348815/modresource/content/1/ $\begin{array}{llllllllllllllllllllll}\mathrm{N} & \mathrm{U} & \mathrm{N} & \mathrm{E} & \mathrm{S} & \% & 2 & \mathrm{C} & \% & 2 & 0 & \mathrm{~A} & \mathrm{~V} & \mathrm{e} & 1 & \% & \mathrm{C} & 3 & \% & \mathrm{~A} & 3 & \mathrm{~s}\end{array}$. $\% 200$ s $\% 20$ tribunais $\% 20 \mathrm{e} \% 20 \mathrm{o} \% 20$ direito $\% 20 \mathrm{a} \% 20 \mathrm{sa} \% \mathrm{C} 3 \%$ BAde.pdf $>$. Acesso: 23 de set. 2017.

PETERS, B. G. American public policy. Chatham, N. J.: Chatham House, 1986.

PIERSON, Paul. Beyond the welfare state: the new political economy of welfare. Cambridge: Polity Press, 1998. 
PIOVESAN, Flávia. Justiciabilidade dos direitos sociais e econômicos: desafios e perspectivas. In: CANOTILHO, J. J.; CORREIA, Marcus O. G.; CORREIRA, Érica P. B.; (Orgs). Direitos fundamentais sociais. São Paulo: Saraiva, 2015, p. 51-68.

SANTOS, Marcia Valquíria Batista et al. O caso da fosfoetanolamina sintética: judicialização com risco a saúde. In: BUCCI, Maria Paula Dallari.; DUARTE, Clarice Seixas. (Orgs). Judicialização da saúde: a visão do Poder Executivo. São Paulo: Saraiva, 2017, p. 139-173.

SCHMITT, Carl. Der hüter der verfassung. Berlin: Duncker \& Humblot, 1996.

SOUZA NETO, Cláudio P. de.; SARMENTO, Daniel. Direito constitucional: teoria, história e métodos de trabalho. Belo Horizonte: Ed. Fórum, 2017.

STRECK, L. L.; MORAIS, José L. B. De. Ciência política e teoria do estado. Porto Alegre: Livraria do Advogado, 2006.

TORRES, Heleno Taveira. Direito constitucional financeiro: teoria da constituição financeira. São Paulo: Revista dos Tribunais, 2014.

TORRES, Marcelo Douglas. Estado, democracia e administração pública no Brasil. Rio de Janeiro, FGV, 2004. 